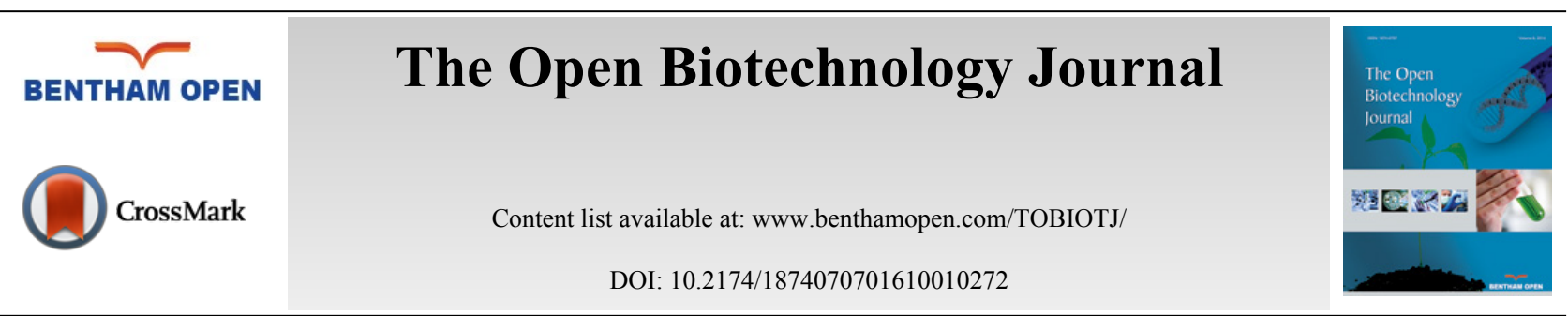

RESEARCH ARTICLE

\title{
The Redefined First, Second and Third Zagreb Indices of Titania Nanotubes $\mathrm{TiO}_{2}[\mathrm{~m}, \mathrm{n}]$
}

\author{
Wei Gao ${ }^{1, *}$, Mohammad R. Farahani ${ }^{2}$, Muhammad K. Jamil ${ }^{3}$ and Muhammad K. Siddiqui ${ }^{4}$ \\ ${ }^{I}$ School of Information Science and Technology, Yunnan Normal University, Kunming 650500, China \\ ${ }^{2}$ Department of Applied Mathematics, Iran University of Science and Technology (IUST) Narmak, Tehran, 16844, Iran \\ ${ }^{3}$ Department of Mathematics, Riphah Institute of Computing and Applied Sciences (RICAS) Riphah International \\ University, 14 Ali Road Lahore, Pakistan \\ ${ }^{4}$ Department of Mathematics, Comsats Institute of Information Technology, Sahiwal, Pakistan
}

Received: March 04, 2016

Revised: July 22, 2016

Accepted: July 26, 2016

Abstract: The first and the second Zagreb indices are two of the most thoroughly studied and oldest topological indices. Recently in 2013, Ranjini et al. re-defined the Zagreb indices, i.e., the redefined first, second and third Zagreb indices of a graph $G$ are defined as

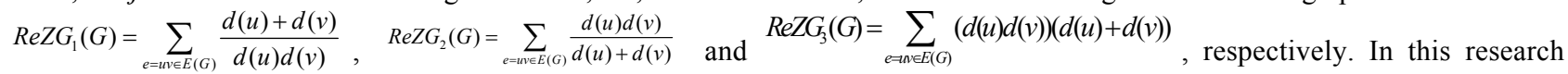
paper, we compute the redefined Zagreb indices of the Titania Nanotubes $\mathrm{TiO}_{2}[m, n]$.

Keywords: Carbon nanotube, Degree of vertex, Molecular graphs, Nano structures, Redefined zagreb indices, Titania nanotubes, Topological indices, Zagreb indices.

\section{INTRODUCTION}

Let $G(V(G), E(G))$ be a simple connected graph. In the setting of chemical graph theory, we use a graph $G$ to model a chemical structures. Namely, we use the vertices and edges in $G$ to represent respectively the atoms and the bonds in chemical structures. The vertex set and edge set of $G$ are denoted by $V(G)$ and $E(G)$ respectively and for $u, v$ $\epsilon V(G) ; e=u v$ is an edge of $G(e \in E(G))$. In a simple connected molecular graph $G$ as order $n, d(v)$ be the vertex degrees of vertices/atom $v$ in $G$. Then $0 \leq \delta(G) \leq d(v) \leq \Delta(G) \leq n-1$, where $\delta(G)$ and $\Delta(G)$ are the minimum and maximum of degrees $d(v)$ for all $v \in V(G)$. The notations and terminologies that were used but were undefined in this paper can be found in $[1,2]$.

A topological index is a real number associated with a graph which characterizes the topology of the graph and is invariant under graph isomorphism. There are many distance or degree based topological indices. Degree based topological indices are of great importance and play a vital role in chemical graph theory. Some recent results on topological indices of chemical graphs have been studied by Gao et al. [3, 4].

The first and second Zagreb indices which were introduced by Gutman and Trinajstić [5] in 1972 are the oldest topological indices of graphs. They are degree based indices and expressed as follows:

$$
\begin{gathered}
M_{1}(G)=\sum_{u v \in E(G)}(d(u)+d(v)), \\
M_{2}(G)=\sum_{u v \in E(G)}(d(u) d(v)) .
\end{gathered}
$$

\footnotetext{
* Address correspondence to this author at the School of Information Science and Technology, Yunnan Normal University, Kunming 650500, China; Tel/Fax: +0871-87646356; E-mail: gaowei@ynnu.edu.cn
} 
In 2012, Ghorbani and Azimi [6] proposed the multiple versions of Zagreb indices of a graph $G$. These new indices are first multiple Zagreb index $P M_{1}(G)$, second multiple Zagreb index $P M_{2}(G)$ and defined as:

$$
\begin{aligned}
& P M_{1}(G)=\prod_{u v \in E(G)}[d(u)+d(v)], \\
& P M_{2}(G)=\prod_{u v \in E(G)}[d(u) \times d(v)] .
\end{aligned}
$$

The reader can find more information about multiple versions of Zagreb indices of some molecular graphs and Nanotubes in [7 - 10].

In 2013, Shirdel et al. [11] introduced another degree based version of topological index named Hyper-Zagreb index and it is defined as:

$$
H M(G)=\sum_{u v \in E(G)}(d(u)+d(v))^{2}
$$

For more study about some properties of hyper Zagreb indices, see [12 - 16].

In 2004, Gutman and Das [17] defined the first and second Zagreb Polynomial in the following way:

$$
\begin{aligned}
& M_{1}(G, x)=\sum_{u v \in E(G)} x^{d(u)+d(v)}, \\
& M_{2}(G, x)=\sum_{u v \in E(G)} x^{d(u) d(v)} .
\end{aligned}
$$

The properties of $M_{1}(G, x), M_{2}(G, x)$ polynomials for some chemical structures have been studied in the literature $[17,18]$.

Ranjini et al. [19] re-defined the Zagreb indices, i.e. the redefined first, second and third Zagreb indices for a graph $G$ and these are manifested as

and

$$
\begin{aligned}
& \operatorname{ReZG}_{1}(G)=\sum_{e=u v \in E(G)} \frac{d(u)+d(v)}{d(u) d(v)}, \\
& \operatorname{ReZG}_{2}(G)=\sum_{e=u v \in E(G)} \frac{d(u) d(v)}{d(u)+d(v)},
\end{aligned}
$$

$$
R e Z G_{3}(G)=\sum_{e=u v \in E(G)}(d(u) d(v))(d(u)+d(v))
$$

respectively.

\section{MAIN RESULTS}

Titania Nanotubes are studied comprehensively in materials science. Carbon nanotube composites have attracted much attention due to their unique properties and promising applications. Titanium dioxide $\left(\mathrm{TiO}_{2}\right)$ is an important semiconductor material, and it has been applied as white pigment, cosmetic, catalyst and carrier owing to its excellent physical and chemical properties. The $\mathrm{TiO}_{2}$ sheets with a thickness of a few atomic layers were found to be remarkably stable [20 - 28]. The graph of the Titania Nanotubes $\mathrm{Ti}_{2}[m, n]$ is presented in Fig. (1), where $m$ denotes the number of octagons in a column and $n$ denotes the number of octagons in a row of the Titania Nanotubes. Malik and Imran [25] computed the first and second Zagreb indices, first and second multiple Zagreb index for an infinite class of Titania Nanotubes $\mathrm{TiO}_{2}[m, n]$.

In this paper, we computed the redefined Zagreb indices of Titania Nanotubes $\mathrm{TiO}_{2}[m, n]$, for this initially we perform some necessary calculations. 


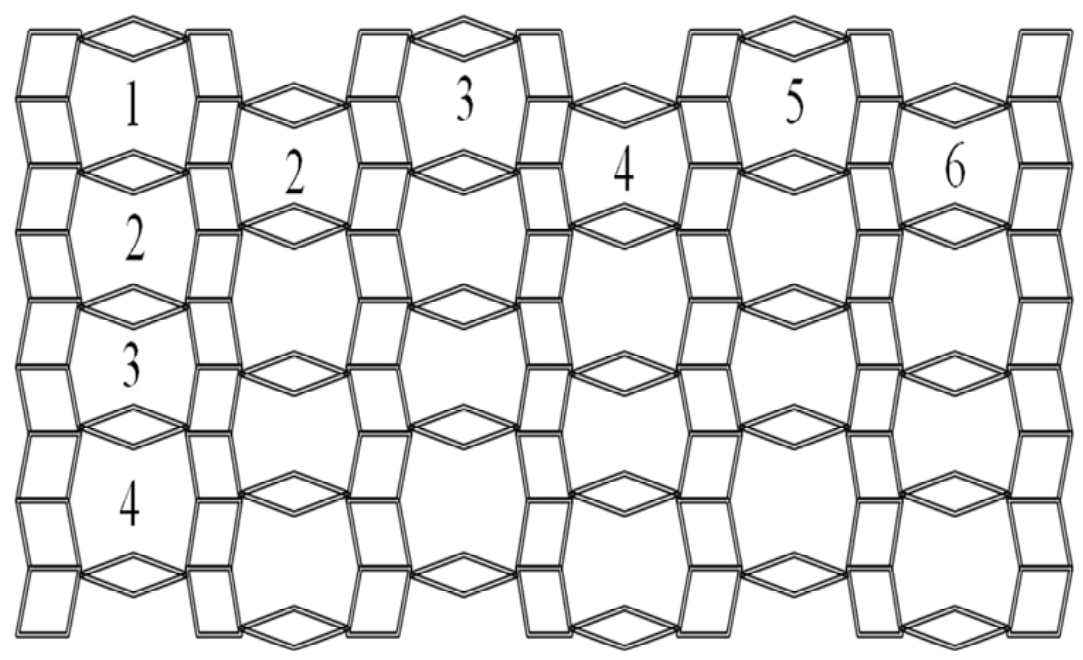

Fig. (1). For $m=4$ and $n=6$, the graph of $\mathrm{TiO}_{2}[m, n]$-Nanotubes.

Let us define the partitions for the vertex set and edge set of Titania Nanotubes $\mathrm{TiO}_{2}[m, n]$, for $\delta(G) \leq a \leq \Delta(G)$, $2 \delta(G) \leq b \leq 2 \Delta(G)$ and $\delta(G)^{2} \leq c \leq \Delta(G)^{2}$, then we have $[25,29,30]$ :

$$
\begin{gathered}
V_{a}=\{v \in V(G) \mid d(v)=a\}, \\
E_{b}=\{e=u v \in E(G) \mid d(u)+d(v)=b\}, \\
E_{c}^{*}=\{e=u v \in E(G) \mid d(u) d(v)=c\} .
\end{gathered}
$$

From $[25,29,30]$, we can see that for all vertex/atom $\mathrm{v}$ in the molecular graph of $\mathrm{TiO}_{2}$ Nanotubes $2 \leq d(v) \leq 5$, thus five vertex partitions of $\mathrm{TiO}_{2}$ with their cardinalities are as follows (see Table 1):

$$
\begin{aligned}
& V_{2}=\{u \in V(G) \mid d(u)=2\}, \\
& V_{3}=\{u \in V(G) \mid d(u)=3\}, \\
& V_{4}=\{u \in V(G) \mid d(u)=4\}, \\
& V_{5}=\{u \in V(G) \mid d(u)=5\} .
\end{aligned}
$$

Table 1. The vertex partitions of the $\mathrm{TiO}_{2}$ Nanotubes along with their cardinalities.

\begin{tabular}{|c|c|c|c|c|}
\hline Vertex partition & $V_{2}$ & $V_{3}$ & $V_{4}$ & $V_{5}$ \\
\hline Cardinality & $2 m n+4 n$ & $2 m n$ & $2 n$ & $2 m n$ \\
\hline
\end{tabular}

The edge partitions of $\mathrm{TiO}_{2}$ Nanotubes with their cardinalities (see Table 2) are stated as follows.

$$
\begin{gathered}
E_{6}=E_{8}^{*}=\{e=u v \in E(G) \mid d(u)=2 \& d(v)=4\}, \\
E_{7}=E_{10}^{*} \cup E_{12}^{*}=\{e=u v \in E(G) \mid d(u)=2 \& d(v)=5\} \cup\{e=u v \in E(G) \mid d(u)=3 \& d(v)=4\}, \\
E_{8}=E_{15}^{*}=\{e=u v \in E(G) \mid d(u)=3 \& d(v)=5\} .
\end{gathered}
$$

Table 2. The edge partitions of the $\mathrm{TiO}_{2}$ Nanotubes along with their cardinalities.

\begin{tabular}{|c|c|c|c|c|c|}
\hline Vertex partition & $E_{6}=E_{8}{ }^{*}$ & $E_{7}$ & $E_{8}=E_{15}{ }^{*}$ & $E_{10}{ }^{*}$ & $E_{12}{ }^{*}$ \\
\hline Cardinality & $6 n$ & $4 m n+4 n$ & $6 m n-2 n$ & $4 m n+2 n$ & $2 n$ \\
\hline
\end{tabular}

For every vertex $v \in V(G), d(v)$ belongs to exactly one class $V_{a}$ for $2 \leq a \leq 5$ and for every edge $u v \in E(G)$, $d(u)+d(v)$ (resp. $d(u) d(v)$ ) belongs to exactly one class $E_{b}$ (resp. $E_{c}{ }^{*}$ ) for $2 \delta(G) \leq b \leq 2 \Delta(G)$ and $\delta(G)^{2} \leq c \leq \Delta(G)^{2}$. So, the vertex partitions $V_{a}$ and the edge partitions $E_{b}$ and $E_{c}{ }^{*}$ are collectively exhaustive, that is:

$$
\bigcup_{a=\delta(G)}^{\Delta(G)} V_{a}=|V(G)|, \quad \bigcup_{b=2 \delta(G)}^{2 \Delta(G)} E_{b}=|E(G)|, \quad \bigcup_{c=\delta^{2}(G)}^{\Delta^{2}(G)} E_{c}^{*}=|E(G)| \text {. }
$$


Now, we compute the redefined first, second and third Zagreb indices of Titania Nanotubes $\mathrm{TiO}_{2}[\mathrm{~m}, n]$ in the following theorems.

Theorem 1: Let be the Titania Nanotubes, then the redefined first Zagreb indices is:

$$
\operatorname{Re} Z G_{1}\left(\mathrm{TiO}_{2}[m, n]\right)=6 n(m+1) .
$$

Proof. In terms of the definition of the revised first Zagreb index, we have:

$$
\begin{aligned}
\operatorname{ReZG}_{1}\left(T_{i} O_{2}[m, n]\right)= & \sum_{e=u v \in E\left(T i O_{2}[m, n]\right)} \frac{d(u)+d(v)}{d(u) d(v)} \\
= & \sum_{e=u v \in E_{8}^{*}\left(T i O_{2}[m, n]\right)} \frac{d(u)+d(v)}{d(u) d(v)}+\sum_{e=u v \in E_{10}^{*}\left(T i O_{2}[m, n]\right)} \frac{d(u)+d(v)}{d(u) d(v)}+ \\
& \sum_{e=u v \in E_{12}^{*}\left(T i O_{2}[m, n]\right)} \frac{d(u)+d(v)}{d(u) d(v)}+\sum_{e=u v \in E_{15}^{*}\left(T i O_{2}[m, n]\right)} \frac{d(u)+d(v)}{d(u) d(v)} \\
= & \frac{6}{8} E_{8}^{*}+\frac{7}{10} E_{10}^{*}+\frac{7}{12} E_{12}^{*}+\frac{8}{15} E_{15}^{*}
\end{aligned}
$$

Form Table 2 we get:

$$
\begin{aligned}
& =\frac{6}{8}(6 n)+\frac{7}{10}(4 m n+2 n)+\frac{7}{12}(2 n)+\frac{8}{15}(6 m n-2 n) \\
& =6 n(m+1)
\end{aligned}
$$

which is the required result.

Theorem 2. Let be the Titania Nanotubes, then the redefined second Zagreb indices is:

$$
\operatorname{Re} Z_{2}\left(T_{i} O_{2}[m, n]\right)=\frac{95 n}{14}\left(\frac{5 m+2}{2}\right)
$$

Proof. By means of the definition of the revised second Zagreb index, we infer:

$$
\begin{gathered}
\operatorname{ReZG}_{2}\left(\mathrm{TiO}_{2}[m, n]\right)=\sum_{e=u v \in E\left(T i O_{2}[m, n]\right)} \frac{d(u) d(v)}{d(u)+d(v)} \\
=\sum_{e=u v \in E_{8}^{*}\left(T i O_{2}[m, n]\right)} \frac{d(u) d(v)}{d(u)+d(v)}+\sum_{e=u v \in E_{10}^{*}\left(T i O_{2}[m, n]\right)} \frac{d(u) d(v)}{d(u)+d(v)}+ \\
\sum_{e=u v \in E_{12}^{*}\left(T i O_{2}[m, n]\right)} \frac{d(u) d(v)}{d(u)+d(v)}+\sum_{e=u v \in E_{15}^{*}\left(T i O_{2}[m, n]\right)} \frac{d(u) d(v)}{d(u)+d(v)} \\
=\frac{8}{6} E_{8}^{*}+\frac{10}{7} E_{10}^{*}+\frac{12}{7} E_{12}^{*}+\frac{15}{8} E_{15}^{*} .
\end{gathered}
$$

From Table 2 we deduce:

$$
\begin{aligned}
& =\frac{8}{6}(6 n)+\frac{10}{7}(4 m n+2 n)+\frac{12}{7}(2 n)+\frac{15}{8}(6 m n-2 n) \\
& =\frac{95 n}{14}\left(\frac{5 m+2}{2}\right)
\end{aligned}
$$


which is the expected result.

Theorem 3. Let $\mathrm{TiO}_{2}[m, n]$ be the Titania Nanotubes, then the redefined third Zagreb indices is:

$$
\operatorname{Re} Z G_{3}\left(\mathrm{TiO}_{2}[m, n]\right)=4 n(250 m+89)
$$

Proof. From the definition of revised third Zagreb index, we yield:

$$
\begin{aligned}
& \operatorname{ReZG}_{3}\left(\mathrm{TiO}_{2}[m, n]\right)=\sum_{e=u v \in E\left(T i O_{2}[m, n]\right)}(d(u)+d(v))(d(u) \times d(v)) \\
& =\sum_{e=u v \in E_{8}^{*}\left(T i O_{2}[m, n]\right)}(d(u)+d(v))(d(u) \times d(v))+\sum_{e=u v \in E_{10}^{*}\left(T i O_{2}[m, n]\right)}(d(u)+d(v))(d(u) \times d(v)) \\
& +\sum_{e=u v \in E_{12}^{*}\left(T i O_{2}[m, n]\right)}(d(u)+d(v))(d(u) \times d(v))+\sum_{e=u v \in E_{15}^{*}\left(T i O_{2}[m, n]\right)}(d(u)+d(v))(d(u) \times d(v)) \\
& =(6)(8) E_{8}^{*}+(7)(10) E_{10}^{*}+(7)(12) E_{12}^{*}+(8)(15) E_{15}^{*}
\end{aligned}
$$

From Table 2 we obtain:

$$
\begin{aligned}
& =48(6 n)+70(4 m n+2 n)+84(2 n)+120(6 m n-2 n) \\
& =4 n(250 m+89)
\end{aligned}
$$

which is the expected result.

\section{CONFLICT OF INTEREST}

The authors confirm that this article content has no conflict of interest.

\section{ACKNOWLEDGEMENTS}

We thank the reviewers for their constructive comments in improving the quality of this paper. This work was supported in part by NSFC (11401519).

\section{REFERENCES}

[1] Harary F. Graph Theory. Reading: Addison-Wesley 1969.

[2] West DB. Introduction to Graph Theory. Upper Saddle River, USA: Prentice Hall 1996.

[3] Gao W, Wang W F, Farahani M R. Topological indices study of molecular structure in anticancer drugs. J Chem 2016 ; 2016 Article ID 3216327, 8 page. [http://dx.doi.org/dx.doi.org/10.1155/2016/3216327]

[4] Gao W, Farahani MR, Shi L. Forgotten topological index of some drug structures. Acta Med Mediter 2016; 32: 579-85.

[5] Gutman I, Trinajstic N. Graph theory and molecular orbitals. Total $\varphi$-electron energy of alternant hydrocarbons. Chem Phys Lett 1972; 17(4): 535-8. [http://dx.doi.org/10.1016/0009-2614(72)85099-1]

[6] Ghorbani M, Azimi N. Note on multiple Zagreb indices. Iran J Math Chem 2012; 3(2): 137-43.

[7] Gao W, Farahani MR, Kamran Jamil M. The eccentricity version of atom-bond connectivity index of linear polycene parallelogram benzenoid ABC5(P(n,n)). Acta Chim Slov 2016; 63(2): 376-9. [http://dx.doi.org/10.17344/acsi.2016.2378] [PMID: 27333562]

[8] Farahani MR, Rajesh Kanna MR. On multiple zagreb indices of armchair polyhex nanotubes. Phy Sci Int J 2016; 9(1): 1-5. [http://dx.doi.org/10.9734/PSIJ/2016/21420]

[9] Farahani MR. On multiple zagreb indices of dendrimer nanostars. Int Lett Chem Phy Astron 2015; 52: 147-51.

[10] Farahani MR, Gao W. On multiple zagreb indices of polycyclic aromatic hydrocarbons PAH. J Chem Pharm Res 2015; 7(10): 535-9. 
[11] Shirdel GH, Pour HR, Sayadi AM. The hyper-Zagreb index of graph operations. Iran J Math Chem 2013; 4(2): 213-20.

[12] Farahani MR. The hyper-zagreb index of benzenoid series. Front Math Appl 2015; 2(1): 1-5.

[13] Farahani MR. Computing the hyper-zagreb index of hexagonal nanotubes. J Chem Mater Res 2015; 2(1): 16-8.

[14] Gao W, Siddiqui MK, Imran M, Jamil MK, Farahani MR. Forgotten topological index of chemical structure in drugs. Saudi Pharm J 2016; 24(3): 258-64. [http://dx.doi.org/10.1016/j.jsps.2016.04.012] [PMID: 27275112]

[15] Gao W, Wang WF. Revised Szeged index and revised edge-szeged index of special chemical molecular structures. J Interdisciplinary Math 2016; 19(3): 495-516. [http://dx.doi.org/10.1080/09720502.2015.1113032]

[16] Gao W, Shi L, Farahani MR. Distance-based indices for some families of dendrimer nanostars. IAENG Int J Appl Math 2016; 46(2): 168-86.

[17] Gutman I, Das KC. The first Zagreb index 30 years after. MATCH Commun Math Comput Chem 2004; 50: 83-92.

[18] Gutman I. New bounds on zagreb indices and the zagreb co-indices. Bol Soc Paran Mat 2013; 31(1): 51-5.

[19] Ranjini PS, Lokesha V, Usha A. Relation between phenylene and hexagonal squeeze using harmonic index. Int J Graph Theory 2013 ; 1 : 116-21.

[20] Ramazani M, Farahmandjou M, Firoozabadi TP. Effect of nitric acid on particle morphology of the $\mathrm{TiO}_{2}$. J Nanosci Nanotechnol 2015; 11(1): $59-62$.

[21] Evarestoy RA, Zhukovskii YF, Bandura AV, Piskunov S. Symmetry and models of single-walled $\mathrm{TiO}_{2}$ Nanotubes with rectangular morphology. Cent Eur J Phys 2011; 9(2): 492-501.

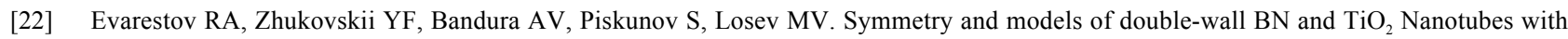
hexagonal morphology. J Phys Chem 2011; 115(29): 14067-76.

[23] Evarestov RA, Zhukovskii YF, Bandura AV, Piskunov S. Symmetry and models of single-wall $\mathrm{BN}$ and $\mathrm{TiO}_{2}$ Nanotubes with hexagonal morphology. J Phys Chem 2010; 114(49): 21061-9.

[24] Imran M, Hayat S, Mailk MY. On topological indices of certain interconnection networks. Appl Math Comput 2014; 244: 936-51. [http://dx.doi.org/10.1016/j.amc.2014.07.064]

[25] Malik MA, Imran M. On multiple Zagreb indices of $\mathrm{TiO}_{2}$ Nanotubes. Acta Chim Slov 2015; 62(4): 973-6. [http://dx.doi.org/10.17344/acsi.2015.1746] [PMID: 26680727]

[26] Gao W, Farahani MR. Degree-based indices computation for special chemical molecular structures using edge dividing method. Appl Math Nonlinear Sci 2016; 1(1): 99-122.

[http://dx.doi.org/10.21042/AMNS.2016.1.00009]

[27] Gao W, Wang WF. Degree-based indices of polyhex nanotubes and dendrimer nanostar. J Comput Theor Nanosci 2016; 13(3): 1577-83. [http://dx.doi.org/10.1166/jctn.2016.5083]

[28] Farahani MR, Jamil MK, Imran M. Vertex PI topological index of Titania Nanotubes. Appl Math Nonlinear Sci 2016; 1(1): $170-5$.

[29] Farahani MR. Some connectivity indices and zagreb index of polyhex nanotubes. Acta Chim Slov 2012; 59(4): 779-83. [PMID: 24061358]

[30] Imrana M, Baigb AQ, Ali H. On molecular topological properties of hex-derived networks. J Chemometr 2016; 30(3): 121-9. [http://dx.doi.org/10.1002/cem.2785]

(C) Gao et al.; Licensee Bentham Open

This is an open access article licensed under the terms of the Creative Commons Attribution-Non-Commercial 4.0 International Public License (CC BY-NC 4.0) (https://creativecommons.org/licenses/by-nc/4.0/legalcode), which permits unrestricted, non-commercial use, distribution and reproduction in any medium, provided the work is properly cited. 